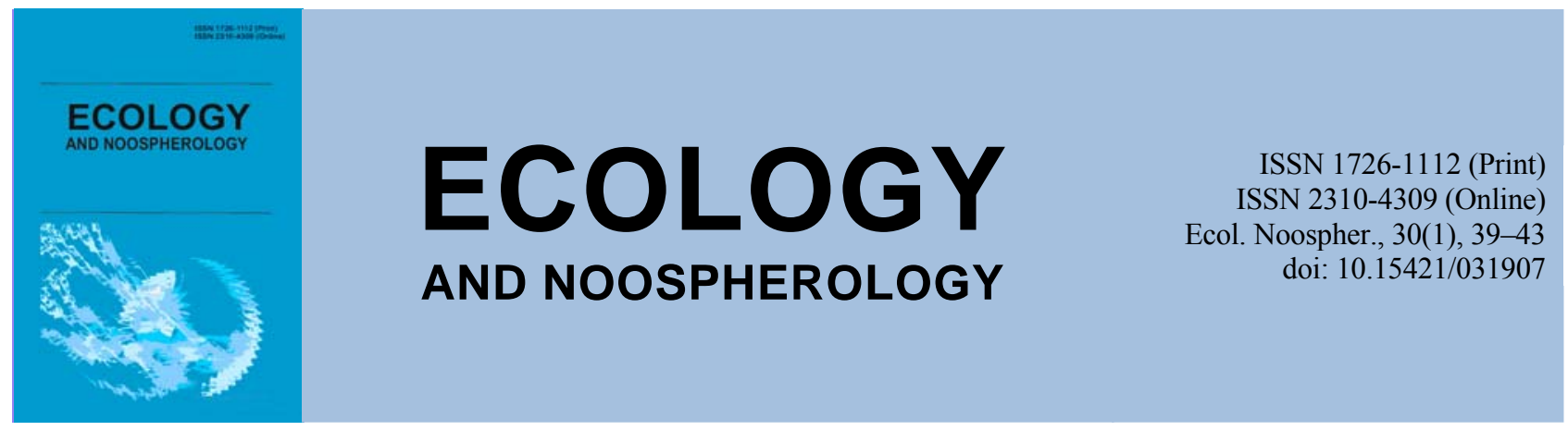

\title{
Ecological and toxicological assessment of the influence of the chemical enterprise on soil
}

\author{
A. N. Krainiukov, I. A. Kryvytska \\ V. N. Karazin Kharkiv National University, Kharkiv, Ukraine
}

Article info

Received 19.02.2019

Received in revised form 28.02.2019

Accepted 06.03.2019

V. N. Karazin Kharkiv National University, Svobody sq., 4, Kharkiv, 61022, Ukraine. Tel.: +38-067-266-43-19 E-mail:alkraynukov@gmail.com
Krainiukov, A. N., Kryvytska, I. A. (2019). Ecological and toxicological assessment of the influence of the chemical enterprise on soil. Ecology and Noospherology, 30(1), 39-43. doi:10.15421/031907

Technogenic pollution of the territory firstly leads to decrease of productivity of the land, since the main part of the technogenic loading, as a result of such pollution, assumes to the soil and vegetation. Soils those have been contaminated are characterized by changed structural and physical-and-chemical properties, which does not allow them to be used for economic purposes. To detect the technogenic loading on the soil as a result of the chemical plant operation, soil quality studies were carried out using the bio-testing method. The most informative data towards ecological danger of ecosystem pollution is the results of the determination of phytotoxicity for soil organisms. Such information can be obtained by an integral assessment of the biological usefulness of the habitat of organisms using the bio-testing method, which provides registration in controlled, standard conditions of the corresponding reactions of test organisms to the toxic effects of ecologically hazardous chemical compounds and their mixes. The following higher plants were selected as test cultures: Raphanus sativus L., Hordeum vulgare L. and Triticum aestivum L. As the test-response of higher plants, the energy of seed germination, the length of the sprout and the length of the root were taken into account. Four zones were selected for the research. The largest difference between the values of germination energy between control and experiment was observed on the results of a test-response to Hordeum vulgare $L$. in a sample of soil from zone $\mathrm{Nr} 4$. The indicator of the toxic effect detected on the territory of zone $\mathrm{Nr} 4-43,64 \%$ reduction in the length of the roots relative to the control; $33.81 \%$ reduction in the length of the germs relative to the control based on the results of the test-response to Hordeum vulgare L. The soil sample from the zone $\mathrm{Nr} 1$ showed no toxic properties in any test reaction $(6.32 \%$ decrease in root length relative to control one, $5.68 \%$ reduction length of germs relative to the control one based on the results of the test reaction on Raphanus sativus $L$. Sample of soil from zone $\mathrm{Nr} 2$ did not show toxicity $(-45.26 \%$ decrease in root length relative to control one and $8.61 \%$ decrease in germination length relative to control one revealed by the results of the test-response to Raphanus sativus $L$. Soil samples from zone $\mathrm{Nr} 3$ also showed no toxicity $(3.83 \%$ decrease in root length relative to control and $11.02 \%$ reduction in germination length relative to control revealed by test-reaction results on Raphanus sativus $L$. The table value of the Student's criterion for the probability level is $\mathrm{P}=0.5$ and the number of measures of freedom 58 is 2.01 . The calculation of the actual value of Student's criterion for the length of the roots (2.68) and the germs (2.05) showed an excess of the table value based on the results of the testresponse on Hordeum vulgare $L$. in the soil sample from zone $\mathrm{Nr} 4$, what confirms the presence of toxic properties of the soil. In order to assess the risk of soil contamination, the "measure of soil contamination" indicator was used in accordance with defined levels of inhibition of growth processes, the quantitative characteristics of which are expressed by the soil contamination coefficient, while the soil contamination coefficient is differentiated according to the levels of inhibition of growth processes. According to the calculated data, in the sample $\mathrm{Nr} 4$, the phytotoxic factor or percentage reduction in the length of the roots relative to the control is $43.64 \%$ based on the results of the test-response to Hordeum vulgare $L$. By level of contamination, the soil is moderately polluted, belongs to the III class of quality and shows the measure of contamination of 1,3. Soil samples №1, №2 and №3 showed no toxicity (A 20), i.e., they are non-contaminated and belong to the I class of quality. Therefore, for the integrated assessment of soil quality, in addition to chemical indicators, it is recommended to use integral indicators, in particular phytotoxicity of the soil, which characterizes the biological usefulness of the habitat of organisms. 


\title{
Еколого-токсикологічна оцінка впливу хімічного підприємства на грунтовий покрив
}

\author{
О. М. Крайнюков, I. А. Кривицька
}

Харківський національний університет імені В. Н. Каразіна, Харків, Украӥна

Техногенне забруднення території призводить в першу чергу до зменшення продуктивності земель, оскільки основну частку техногенного навантаження внаслідок такого забруднення приймають на себе грунтовий і рослинний покрив. Для земель і грунтів, які зазнали забруднення, характерні змінені структурні і фізико-хімічні властивості, що не дозволяє їх використовувати в господарських цілях. 3 метою виявлення техногенного навантаження в результаті виробничої діяльності хімічного підприємства на грунтовий покрив було проведено дослідження якості грунтів методом біотестування. Як тесткультуру було обрано вищі рослини: редьку (Raphanus sativus L.), жито (Hordeum vulgare L.) та пшеницю (Triticum aestivum L.). Як тест-реакції вищих рослин враховувалася енергія проростання насіння, довжина паростка і довжина кореня. Для проведення дослідження було обрано 4 ділянки. Найбільша різниця значень енергії проростання між контролем та дослідом спостерігалася за результатами тест-реакції на Hordeum vulgare L. у зразку грунту з ділянки № 4. Визначено, що токсичний ефект виявлено на території ділянки № $4-43,64$ \% зменшення довжини коренів відносно контролю; 33,81 \% зменшення довжини паростків відносно контролю за результатами тест-реакції на Hordeum vulgare L. Для оцінки небезпеки забруднення грунтів використано показник «ступінь забрудненості грунтів» у відповідності до визначених рівнів пригнічення ростових процесів, кількісна характеристика якого виражається коефіцієнтом забрудненості грунтів, при цьому коефіцієнт забрудненості грунтів диференціюють за рівнями пригнічення ростових процесів. За розрахованими даними, у зразку № 4 фітотоксичний фактор або відсоткове значення зменшення довжини коренів відносно контролю дорівнює 43,64 \% за результатами тест-реакції на Hordeum vulgare L. За рівнем забрудненості грунт є помірно забрудненим, відноситься до III класу якості та виявляє ступінь забрудненості 1,3. Зразки грунту № 1, № 2 та № 3 не виявили токсичності (А<20), тобто за рівнем забрудненості вони $є$ незабрудненими, відносяться до I класу якості.

Ключові слова: біотестування; фітотоксичність; грунтовий покрив; ступінь забрудненості; тест-реакції

\section{Вступ}

Сучасні фізичні і фізико-хімічні методи аналізу компонентів навколишнього середовища дозволяють високоефективно, диференційовано по забруднюючих компонентах давати кількісну і якісну оцінку впливу виробничої діяльності підприємств на навколишне середовище, зокрема на грунтовий покрив. При оцінці якості грунтів, які $є$ середовищем існування складних біоценозів, що обумовлює перебіг процесів на біофізичному, біохімічному рівнях та на рівнях внутрішньо- i міжпопуляційної взаємодії, не завжди можливо оцінити кількісний склад усіх компонентів, що забруднюють грунт, також майже неможливо передбачити відгук біотичної складової грунтового покриву на забруднення. У цьому плані більш перспективними $\epsilon$ інтегральні методи, зокрема біотестування.

На цей час природоохоронні заходи 3 регулювання й обмеження надходження у природне середовище екологічно небезпечних речовин і сполук, як правило, засновано на зіставленні фактичних значень їх вмісту 3 установленими величинами ГДК цих речовин для відповідного компоненту природного середовища. Але при цьому використання лише інформації щодо перевищення ГДК окремих хімічних речовин недостатньо для оцінки екологічного стану території, оскільки не враховується вплив сукупної дії полікомпонентних хімічних сполук на біотичну складову екосистем (Krainiukova, 2006).

Доцільність використання біологічних методів для оцінки якості компонентів ландшафту підкреслюється в роботах вітчизняних і зарубіжних авторів (Lukyanenko, 1983; Steinhauser, 1992). Зокрема, у роботі Clement (2004) при визначенні переліку показників для оцінки якості поверхневих вод в умовах антропогенного навантаження рекомендується використовувати поряд 3 іншими біологічні методи: «...біоіндикація і біотестування, на відміну від відомих аналітичних методів контролю за станом середовища, $\epsilon$ незамінними $у$ визначенні токсичності і шкідливості факторів для живих організмів, адже ці характеристики є біологічними, а тому визначають біологічну повноцінність (або неякісність) середовища».
У роботі Monteiro (2009) наведено дані щодо біохімічних змін, які можуть бути використані в інтегральних екотоксикологічних тестах на кадмії (Cd). Ці показники можуть стати основою комплексу біомаркерів для моніторингу та прогнозування ранніх ефектів впливу $\mathrm{Cd}$ на рослини.

У праці Wang (2005) досліджено екотоксикологічний вплив $\mathrm{Cd}$ на три африканські декоративні рослини: календулу (Tagetes erecta L.), шавлію блискучу (Salvia splendens Sellow ex Schult) та солодкий гібіскус (Abelmoschus manihot L.). Результати показали, що $\mathrm{Cd}$ практично не впливає $(p>0.05)$ на проростання насіння всіх рослин і довжину паростків блискучої шавлії (S. splendens Sellow ex Schult). Але мав значний $(p<0,05)$ інгібуючий вплив на довжину коренів цих рослин і довжину паростків календули (T. erecta L.).

Для визначення екотоксикологічного порогу 2,4,6тринітротолуолу (ТНТ) у роботі Gong (1999) проводили експериментальні дослідження 3 проростання насіння із застосуванням репрезентативних видів вищих рослин двох дводольних (Lepidium sativum L., Brassica campestris L.) і двох однодольних (Avena Sativa L., Triticum aestivum L.). Визначено, що фітотоксичність ТНТ впливає на властивості грунту і залежить від виду рослин. Крес-салат i ріпа показали більш високу чутливість до ТНТ, ніж овес $\mathrm{i}$ пшениця.

Для кількісної оцінки інгібуючого впливу металів на насіння пшениці (Triticum aestivum L.) і огірка (Cucumis sativus L.) був проведений експеримент із застосуванням різних концентрацій $\mathrm{Hg}, \mathrm{Cd}, \mathrm{Co}, \mathrm{Cu}, \mathrm{Pb}$ i $\mathrm{Zn}$ (Munzuroglu, 2002). I хоча ефективні концентрації цих металів для певного ступеня інгібування були різними, обидві рослини мали знижену швидкість проростання насіння та кореневу довжину зі збільшенням концентрацій. Визначено, що ртуть $\epsilon$ найбільш гальмівним металом за цими параметрами. Жоден інший метал не викликав такого роду інгібування навіть при найвищій концентрації.

Мета наших досліджень полягала у здійсненні екологотоксикологічної оцінки якості грунтів у межах впливу хімічного підприємства - ПРАТ «Харківський коксовий завод». 


\section{Матеріали та методи досліджень}

Підприємство ПРАТ «Харківський коксовий завод» знаходиться в Основ'янському районі м. Харкова. Завод сконцентровано на одному майданчику. Площа земельної ділянки, зайнятої забудовою основними i допоміжними цехами по периметру огорожі заводу, становить 17,2 га.

Проммайданчик, на якому розташовано виробниче устаткування підприємства, має рівний рельєф території та знаходиться на одному рівні 3 прилеглою територією міста. Із західного боку підприємства протікає річка Уди, 3 північного сходу - проходить магістральний залізничний коридор Укрзалізниці «Харків-Південь-Схід України», 3 південного сходу - р. Лопань. У безпосередній близькості від підприємства розташовані промислові підприємства: ЗАТ «Термолайф»; МОСВ № 1 (Диканівські очисні споруди); ПАТ ХЛФЗ «Червоний хімік».

Характеристика викидів забруднюючих речовин в атмосферне повітря від стаціонарних джерел ПРАТ «Харківський коксовий завод» представлена на підставі проведеної УХІНом у 2017 р. інвентаризації викидів забруднюючих речовин ПРАТ «Харківський коксовий завод» (табл. 1).

Таблиця 1

Перелік видів і обсягів забруднюючих речовин від стаціонарних джерел ПРАТ «Харківський коксовий завод»

\begin{tabular}{clccc}
\hline $\begin{array}{c}\text { № } \\
\text { з/п }\end{array}$ & Найменування забруднюючої речовини & $\begin{array}{c}\text { Клас } \\
\text { небезпеки }\end{array}$ & $\begin{array}{c}\text { Фактичний } \\
\text { обсяг викидів у } \\
2017 \text { р. (т/рік) }\end{array}$ & $\begin{array}{c}\text { Порогові значення } \\
\text { потенційних викидів для взяття } \\
\text { на державний обсяг (т/рік) }\end{array}$ \\
\hline 1 & Речовини у вигляді суспензованих твердих & 3 & 37,459 & 1,0 \\
2 & частинок, не диференційованих за складом & 3 & 77,062 & 1,0 \\
3 & Оксид азоту & 4 & 10,035 & 1,5 \\
4 & Діоксид сірки & 3 & 246,263 & 0,03 \\
5 & Сірководень & 2 & 0,860 & 1,5 \\
6 & Оксид вуглецю & 4 & 35,455 & 0,05 \\
7 & Бензол & 2 & 1,74 & 0,1 \\
8 & Фенол & 2 & 0,755 & 0,2 \\
9 & Водню ціанід & 2 & 0,616 & \\
\end{tabular}

Згідно з табл. 1 такі речовини, як оксид азоту, аміак, сірки діоксид, оксид вуглецю, сірководень, бензол, фенол, водню ціанід та речовини у вигляді суспендованих твердих частинок, не диференційованих за складом, перевищують порогові значення потенційних викидів для взяття на державний обсяг.

\section{Результати та їх обговорення}

3 метою виявлення техногенного навантаження в результаті виробничої діяльності хімічного підприємства на довкілля було проведено дослідження грунтів методом біотестування (Krainiukova, 1997). Як тест-культури було обрано вищі рослини: редьку (Raphanus sativus L.), жито (Hordeum vulgare L.) та пшеницю (Triticum aestivum L.). Як тест-реакції вищих рослин враховувалася енергія проростання насіння, довжина паростка і довжина кореня.
Для проведення дослідження було обрано 4 ділянки. Таке розташування майданчиків дозволило найбільш повно охопити територію навколо досліджуваного підприємства.

Перша ділянка - 1500 м на південний схід від проммайданчика ПРАТ «Харківський коксовий завод», заплава р. Лопань; друга ділянка - 50 м на північ від проммайданчика ПРАТ «Харківський коксовий завод»; третя ділянка - 1200 м на північний схід від проммайданчика ПРАТ «Харківський коксовий завод», житловий масив «Новожаново»; четверта ділянка - 500 м на північ від проммайданчика ПРАТ «Харківський коксовий завод», район заводу «Червоний хімік».

Для розрахунку енергії проростання (табл. 2) порівнювалась кількість пророслого насіння у досліді та контролі, порівняно із загальною кількістю (30) висадженого насіння.

Таблиця 2

Значення тест-реакції вищих рослин при біотестуванні грунтів

\begin{tabular}{|c|c|c|c|c|c|c|}
\hline & \multicolumn{6}{|c|}{ Енергія проростання, \% } \\
\hline & \multicolumn{2}{|c|}{ Hordeum vulgare L. } & \multicolumn{2}{|c|}{ Raphanus sativus L. } & \multicolumn{2}{|c|}{ Triticum aestivum L. } \\
\hline & Дослід & Контроль & Дослід & Контроль & Дослід & Контроль \\
\hline Зразок 1 & 100 & \multirow{4}{*}{93,3} & 66,7 & \multirow{4}{*}{60} & 96,7 & \multirow{4}{*}{96,7} \\
\hline Зразок 2 & 86,7 & & 66,7 & & 96,7 & \\
\hline Зразок 3 & 96,7 & & 56,7 & & 96,7 & \\
\hline Зразок 4 & 80 & & 76,7 & & 100 & \\
\hline
\end{tabular}

3 таблиці можна побачити, що енергія проростання майже у всіх пробах у контролі менша, ніж значення у досліді. Найбільша різниця значень енергії проростання між контролем та дослідом спостерігається за результатами тест-реакції на Hordeum vulgare L. у зразку № 4 (у досліді на 13,3\% менше пророслого насіння, ніж у контролі). Це дає змогу стверджувати, що мають місце токсичні властивості зразку грунту з ділянки № 4 .
Таким чином, у результаті фітотестування встановлено неоднозначну зміну значення енергії проростання як однієї 3 основних тест-реакцій рослинної продукції на дію полютантів. У цілому спостерігається значне зниження енергії проростання Raphanus sativus L. (редьки), що значно знижує рівень використання даного тест-об'єкту у подібних тестуваннях.

Динаміку визначення токсичності тест-об'єктів можна побачити на рис. 1. 


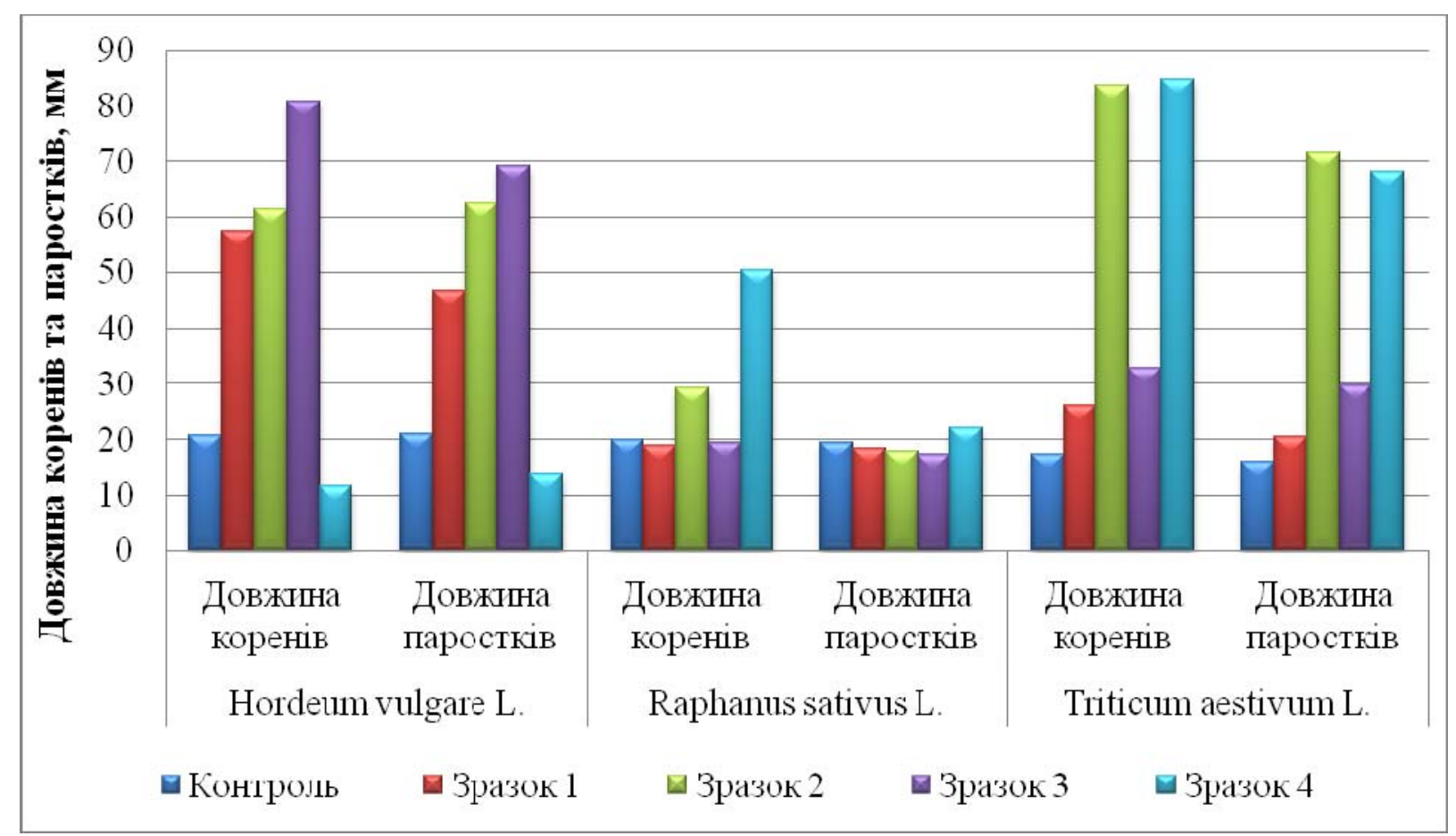

Pис. 1. Визначення довжини коренів і паростків насіння Hordeum vulgare L., Raphanus sativus L. та Triticum aestivum L. відносно контролю

Показник токсичного ефекту виявлений на території ділянки № 4 - 43,64 \% зменшення довжини коренів відносно контролю; 33,81 \% зменшення довжини паростків відносно контролю за результатами тест-реакції на Hordeum vulgare L. Зразок грунту з ділянки № 1 не виявив токсичних властивостей за жодною тест-реакцією $(6,32 \%$ зменшення довжини коренів відносно контролю; 5,68 \% зменшення довжини паростків відносно контролю за результатами тест-реакцій на Raphanus sativus L.). Зразок грунту з ділянки № 2 не виявив токсичності (-45,26\% зменшення довжини коренів відносно контролю та 8,61 \% зменшення довжини паростків відносно контролю виявлено за результатами тест-реакції на Raphanus sativus L.). Зразок грунту з ділянки № 3 також не виявив токсичності (3,83\% зменшення довжини коренів відносно контролю та $11,02 \%$ зменшення довжини паростків відносно контролю виявлено за результатами тест-реакції на Raphanus sativus L.).

Таблиця 3

Індекс інтегральної фітотоксичності
Табличне значення критерію Стьюдента для рівня вірогідності $\mathrm{P}=0,5$ і числа ступенів свободи 58 становить 2,01 . Розрахунок фактичного значення критерію Стьюдента за довжиною коренів $(2,68)$ та паростків $(2,05)$ показав перевищення табличного значення за результатами тестреакції на Hordeum vulgare L. у зразку грунту з ділянки № 4, що підтверджує наявність токсичних властивостей грунту.

Індекс інтегральної фітотоксичності дає змогу визначити вплив водних витяжок із забрудненого грунту на тест-реакції вищих рослин більш об'єктивно.

Тому для отримання комплексної оцінки тестування визначали індекс фітотоксичності:

$$
I \Phi=l g\left[\frac{\left(I_{\Pi}+I_{K}+B_{\Pi}\right)_{\text {meard }}}{\left(I_{\Pi}+I_{K}+B_{\Pi}\right)_{\text {namp }}}\right],
$$

де ДП - довжина паростків; ДК - довжина коренів; $\mathrm{E}_{\Pi}-$ енергія проростання.

Результати розрахунку ІФ наведено в табл. 3.

\begin{tabular}{cccc}
\hline & & Індекс фітотоксичності (ІФ) & \\
& Hordeum vulgare L. & Raphanus sativus $\mathrm{L}$. & Triticum aestivum L. \\
\hline Зразок 1 & 0,17 & 0,017 & 0,05 \\
Зразок 2 & 0,18 & 0,057 & 0,3 \\
Зразок 3 & 0,25 & $-0,045$ & 0,1 \\
Зразок 4 & $-0,12$ & 0,18 & 0,29 \\
\hline
\end{tabular}

За розрахунками найменший показник індексу фітотоксичності виявлено у зразку № $4(-0,12)$, що свідчить про наявні токсичні властивості грунту.

Для оцінки небезпеки забруднення грунтів використано показник «ступінь забрудненості грунтів» (Kryvytska, 2017) у відповідності до визначених рівнів пригнічення ростових процесів, кількісна характеристика якого виражається коефіцієнтом забрудненості грунтів, при цьому коефіцієнт забрудненості грунтів диференціюють за рівнями пригнічення ростових процесів (табл. 4).
Перевага такого підходу у порівнянні з відомим полягає у тому, що таким чином можна визначити не тільки наявність або відсутність фітотоксичного ефекту, а також оцінити небезпеку забруднення грунтів токсичними речовинами через кількісну оцінку забрудненості грунтів в залежності від рівнів пригнічення ростових процесів (Kryvytska, 2017).

За рівнем пригніченості ростових процесів розраховано коефіцієнт забрудненості грунтів (табл. 4).

Порівняємо розраховані значення 3 класифікацією якості грунтів за ступенем забрудненості (табл. 5). 
Таблиця 4

Коефіцієнт забрудненості грунтів

\begin{tabular}{ccccccc}
\hline & \multicolumn{2}{c}{ Hordeum vulgare L. } & \multicolumn{2}{c}{ Raphanus sativus L. } & \multicolumn{2}{c}{ Triticum aestivum L. } \\
& Корінь & Паросток & Корінь & Паросток & Корінь & Паросток \\
\hline Зразок 1 & $-177,46$ & $-122,22$ & 6,32 & 5,68 & $-49,04$ & $-27,80$ \\
Зразок 2 & $-197,42$ & $-197,94$ & $-45,26$ & 8,61 & $-380,27$ & $-344,81$ \\
Зразок 3 & $-290,02$ & $-229,37$ & 3,83 & 11,02 & $-88,89$ & $-85,68$ \\
Зразок 4 & 43,64 & 33,81 & $-151,08$ & $-14,11$ & $-387,16$ & $-323,44$ \\
\hline
\end{tabular}

Таблиия 5

Класифікація якості грунтів за ступенем забрудненості (Kryvytska, 2017)

\begin{tabular}{clcc}
\hline Клас якості & Рівень забрудненості грунтів & $\begin{array}{c}\text { Рівні пригнічення ростових процесів } \\
\text { (фітотоксичний фактор) }\end{array}$ & $\begin{array}{c}\text { Ступінь } \\
\text { забрудненості }\end{array}$ \\
\hline I & Незабруднені & $0-20$ & 1,1 \\
II & Слабкозабруднені & $20,1-40,0$ & 1,2 \\
III & Помірно забруднені & $40,1-60,0$ & 1,3 \\
IV & Брудні & $60,1-80,0$ & 1,4 \\
V & Дуже брудні & $80,1-100,0$ & 1,5 \\
\hline
\end{tabular}

За розрахованими даними, у зразку № 4 фітотоксичний ефект або відсоткове значення зменшення довжини коренів відносно контролю дорівнює 43,64 \% результатами тест-реакції на Hordeum vulgare L. Отже, за рівнем забрудненості грунт $€$ помірно забрудненим, відноситься до III класу якості та виявляє ступінь забрудненості 1,3. Зразки грунту № 1, № 2 та № 3 не виявили токсичності (А 20), тобто за рівнем забрудненості вони $є$ незабрудненими, відносяться до I класу якості та виявляють ступінь забрудненості 1,1.

При проведенні досліду на визначення фітотоксичності методом біотестування було визначено, що даний метод $\epsilon$ досить ефективним. Досить частими є випадки, коли проведений сучасними засобами хімічний аналіз не виявляе порушень нормативних вимог до якості компонентів довкілля, на відміну від використання реакцій відповідних тест-організмів на сумісний вплив речовин, присутніх у середовищі, яке оцінюється.

\section{Висновки}

1. Найбільш інформативними даними щодо екологічної небезпеки забруднення екосистеми $€$ результати визначення фітотоксичності для організмів грунту. Таку інформацію можна отримати шляхом інтегральної оцінки біологічної повноцінності середовища мешкання живих істот за допомогою методу біотестування, який передбачає реєстрацію в контрольованих, стандартних умовах відповідних реакцій тест-організмів на токсичну дію екологічно небезпечних хімічних сполук та їх сумішей.

2. Екотоксикологічні експерименти показали, що на території, яка знаходиться у межах впливу хімічного підприємства, виявлено токсичність $(43,64 \%$ зменшення довжини коренів відносно контролю; $33,81 \%$ зменшення довжини паростків відносно контролю за результатами тестреакції на Hordeum vulgare L.) на ділянці № 4 .

3. За розрахунками найменший показник індексу фітотоксичності виявлено у зразку грунту 3 ділянки № 4 $(-0,12)$ та у зразку № $3(-0,045)$, що свідчить про наявну токсичність. За рівнем забрудненості грунт з ділянки № $4 \epsilon$ помірно забрудненим, відноситься до III класу якості та виявляє ступінь забрудненості 1,3. Зразки № 1, № 2 та № 3 не виявили токсичності $(\mathrm{A}<20)$, тобто за рівнем забрудненості вони є незабрудненими, відносяться до I класу якості та виявляють ступінь забрудненості 1,1.

\section{References}

Gong, P., Wilke, B., Fleischmann, S. (1999). Soil-based phytotoxicity of 2,4,6-trinitrotoluene (TNT) to terrestrial higher plants. Arch Environ Contam Toxicol, 36(2), 152-157.

Klymenko, M. O., Trusheva, S. S., Hrokhovska, Yu. R. (2004). Vidnovna hidroekolohiya porushenykh richkovykh ta ozernykh system (Hidrokhimiya, hidrobiolohiya, hidrolohiya, ekolohiya, upravlinnya) [Reducing the hydro-ecology of disturbed river and lake systems (Hydrochemistry, hydrobiology, hydrology, ecology, management]. Rivne (in Ukrainian).

Kraynyukova, A. M. (1997). Metodyka vyznachennya toksichnosti gruntiv na vyshchykh roslynakh [Method of determining soil toxicity on higher plants]. UKRNDIEP, Kyiv (in Ukrainian).

Kraynyukova, A. M. (2006). Biotestuvannya - metod otsinky tsiyeyi toksychnoyi vlastivostey komponentiv pryrodnoho seredovyshcha ta dzherel yikh zabrudnennya. Problemy okhorony navkolyshnoho pryrodnoho seredovyshcha ta ekolohichnoyi bezpeky [Biotesting - a method for evaluating the toxic properties of the components of the environment and sources of their contamination. Problems of the protection of the environment and ecological safety]. Rayder, Kharkiv (in Ukrainian).

Lukyanenko, V. I. (1983). Teoretychni pytannya biotestuvannya. [Theoretical questions of biotesting]. Volgograd truth, Volgograd (in Russian).

Monteiro, M. S., Santos, C., Soares, A. M., Mann, R. M. (2009). Assessment of biomarkers of cadmium stress in lettuce. Ecotoxicol Environ Saf, 72(3), 811-818.

Munzuroglu, O., Geckil, H. (2002). Effects of metals on seed germination, root elongation, and coleoptile and hypocotyl growth in Triticum aestivum and Cucumis sativus. Arch Environ Contam Toxicol, 43(2), 203-213.

Patent na korysnostey model № 113560. Sposob vyznachennya stupeniv zabrudnenosti gruntiv [Method of determining the degree of soil contamination] / O. M. Kraynyukov, I. A. Kryvytska; zareyestrovano $\mathrm{v}$ derzhavnomu Reyestri patentiv Ukrayiny na Korysni modeli 10.02 .2017 . (19) UA. (11) 113560 (13) U (51) MPK (2017) G01N 33/24 (2006.01) (in Ukrainian).

Steinhauser, K. G., Hansen P. D. (1992). Biologische Testverfahren. Stutgart: Gustav-Fisher Verlad. 884 s.

Wang, X-F, Zhou Q.X. (2005). Ecotoxicological effects of cadmium on three ornamental plants. Chemosphere, 60, 16-21. 